\title{
Viewpoints on Education in the Thought of Phan Boi Chau
}

\author{
D.O.I - 10.51201/Jusst12557 \\ http://doi.org/10.51201/Jusst12557 \\ ${ }^{1}$ Dr. Trinh Thi Kim Chi $\&{ }^{2}$ Dr.Trinh Thanh Tung \\ ${ }^{1,2}$ University of Social Sciences and Humanities -Vietnam National University Ho Chi Minh City, \\ Vietnam
}

\begin{abstract}
One of the important ideas in the ideological system of Phan Boi Chau (1867-1940) - the typical thinker, revolutionary of Vietnam at the end of the nineteenth century and early twentieth century was education. In the view of education, Phan Boi Chau not only specifies the purpose, object, and content of the education, but also points out the methods to expand intellectuals, improve personality, improve spirit and will. of Vietnamese; from there to stand up and expel the French colonialists, regain independence and freedom for the nation, build the country more and more prosperous, demonstrating the profound human value in Phan Boi Chau's thought.
\end{abstract}

Keywords: Phan Boi Chau, views on education, educational purposes, educational role, educational content, educational methods.

\section{INSTRUCTION}

On the basis of the characteristics and requirements of the history of Vietnamese society in the late nineteenth and early twentieth century's, by inheriting human values in the cultural tradition of the Vietnamese people, as well as selectively absorbing refining the humanistic spirit in Eastern and Western culture, human values in Phan Boi Chau's ideology have been formed and developed.

"Humanity", originally means human beauty, or more broadly, human culture. Humanism is a humancenteredism that emphasizes the dignity and dignity of the human person.Along with the views that promote the role, human values and the love, respect for people, love of race and country; especially the thought of human liberation, Phan Boi Chau's point of view on human perfection education is also one of the contents expressing the spirit and deep human values. If you ignore the limitations due to the institutions of historical conditions, Phan Boi Chau's educational stance still has certain meaning for the education and training career in Vietnam today.

To clarify the content of Phan Boi Chau's educational perspective, the article will focus on clarifying the main issues: 1) Phan Boi Chau's point of view on the necessity, the role and meaning of educational development in Vietnam, late 19th century early 20th century; 2) Phan Boi Chau's point of view on the content and method of education and some conclusions and assessments of educational importance in Phan Boi Chau's thought.

\section{MATERIALS AND METHODS}

Purpose: The research to clarify the view of education, Phan Boi Chau not only specifies the purpose, object, and content of the education, but also points out the methods to expand intellectuals, improve personality, improve spirit and will of Vietnamese.

Methodology: The paper's approach is based on the worldview and the methodology of Marxist philosophy, and at the same time uses specific research methods such as analysis and synthesis, logic and history, inductive and interpretation, abstraction, generalization, comparison, comparison and literary methods for research and presentation. 
Main Findings: The research to clarify the content of Phan Boi Chau's educational perspective, through the main issues: 1) Phan Boi Chau's point of view on the necessity, the role and meaning of educational development in Vietnam, late 19th century early 20th century, demonstrating the profound human value in Phan Boi Chau's thought; 2) Phan Boi Chau's point of view on the content and method of education and some conclusions and assessments of educational importance in Phan Boi Chau's thought.

\section{LITERATURE SURVEY}

Can generalize researches, assessments on educational ideology of Phan Boi Chau in the following topics: The first topic is the research works on the conditions, the foundation for formation, the main content and characteristics in educational ideology of Phan Boi Chau, including: Research of Phan Boi Chau by Chuong Thau (editor), Publishing House National Politics, Hanoi, 2004; Phan Boi Chau about the author and works of Chuong Thau and Tran Ngoc Vuong, Publisher Education, Hanoi, 2007; Phan Boi Chau's work, people and career, Publisher Hanoi National University, 1997... Especially, research on Phan Boi Chau has also attracted many foreign scientists. In France, there were monographs on Phan Boi Chau by G. Buodarel such as: Mèmoires de Phan Boi Chau, France - Asie / Asia XXIII - 4, 1969; or Phan Boi Chau et la société Vietnamienne de son temps, France-Asia / Asia XXIII - April 1969. In the US since the end of the twentieth century, there was David G's anti-colonial movement in Vietnam from 1885 to 1925. Marn and the 100th Anniversary of the Journey to the West Movement: Phan Boi Chau Cuong De by Do Minh Thong ... In Germany, at the Institute of Southeast Asian History, Passaw University, in 1987, Professor Bernard Dam gave topic: Phan Boi Chau - Vietnamese cultural house, Vietnam national movement and its relations with Japan and Asia: Thought of Phan Boi Chau, the world revolution, including 2 volumes by Shiraishi Masaya (by Translated by Nguyen Nhu Diem, translated by Tran Son, revised by Chuong Thau), Publisher. National Politics, Hanoi, 2000 ...

The second topic is the research, analysis, assessment and evaluation of educational ideology of Phan Boi Chau, including: The development of thought in Vietnam from the nineteenth century to the August Revolution, 3 volumes by Tran Van Giau, Publishing House National Politics, Hanoi, 1997; Phan Boi Chau - patriotism, cultural house of Chuong Thau, Culture - Information Publishing House, Hanoi, 2012; Phan Boi Chau's thoughts on personality issues, Journal of Social Sciences, No. 12 (136), 2009, Phan Boi Chau's thoughts on education, Journal of Social Sciences, No. 4 (128), 2009...

\section{RESULTS \& DISCUSSIONS}

\section{The necessity and the role, meaning of education in Phan Boi Chau's thought}

As a great culturalist and an ardent revolutionary, with great patriotism, love for the people and noble national self-esteem, Phan Boi Chau is very interested in educating the people of Vietnam. Moreover, in the process of very exciting revolutionary and neo-revolutionary practice activities, Phan Boi Chau has many conditions to observe, learn from, and draw on educational experiences of other countries; and also from that practice has made him very aware of the role and necessity of education for the struggle for national liberation and national construction. According to Phan Boi Chau, education is not only a mold to train and train people, thereby expanding knowledge, developing the soul and personality of Vietnamese people, but also a basis for improving the spirit, patriotism and national awareness, contribute to the development of perfect Vietnamese people. Phan Boi Chau affirmed that education is to make "the people will expand, the people will grow, the civil rights will flourish" (Phan, 2000b: 179) - one of the bases and methods to maintain, revolution, and expel the French, liberating the people and people of Vietnam, building and constructing our country to be strong and prosperous. Education, according to Phan Boi Chau, is also the root for building the socio-political system. Therefore, in Tan Viet Nam's work, Phan Boi Chau wrote: "Education is a mold of people. Quan, the soldiers also came out from there. Education is also the root for building politics. Taxes, criminal law, everything is due to that"(Phan, 2000b: 184). 
But according to Phan Boi Chau, education has become a very basic and urgent task for our country, not only because of its great role in human improvement and the country's development, but also because The people of our country are still immersed in ignorance, darkness, making the people poor, the people are weak, and their lives are poor; people only know to resign, obey, provide for the poets and mercenaries. That is the condition for the French colonialists to rule and oppress our country, and the cause for the rulers to overpower and exploit our people. Phan Boi Chau wrote: "The people of our country today are still immersed in a deep sleep, and are also nestled in foolishness and delusion" (Phan, 2000b: 121).He was heartbroken, worried about the miserable life, low qualifications, weak spirit, backward consciousness, myopic vision of our people. In addition to the ordinary life of food, boys and girls, people do not know civil rights, national destiny and career; In addition to the narrow life, surrounded by their own doors and villages, people do not know any other world. Phan Boi Chau wrote: "Our people are stupid and foolish, do not know how to win the nation and keep their national destiny. Only day and night worrying with all my heart and soul bringing my fat and blood to the poets, do not drink and swallow! Alas! How pitiful!" (Phan, 2000b: 179); and "beyond our village's doorstep, our people don't know what world there is; besides eating and drinking, I don't know what career there is. How stupid" (Phan, 2000b: 122).Not only that, since the invasion and rule of our country, with the guise of "civilizing", the French colonialists have used a malicious policy of ignorance, not paying attention to educational development; on the one hand, they still advocate for maintaining a rogue education; and on the other hand, more than that, after that they focused on building a slave education, making our people only obediently obediently, so that they could easily rule. In the work Thien ho! De ho! Phan Boi Chau has pointed out the intentions of the French colonialists, saying: "Since the loss of the country, of course the French not only did not give the Vietnamese a good education, but they increasingly forced people Vietnam follows a slave and horse education. When first conquering Vietnam, the French encouraged the lessons learned from chapters and faculties, such as ancient literature, poetry, support training, literature" (Phan, 2000d: 280).

As for the later education that the French colonialists put into practice in our country, Phan Boi Chau said that it was just a stupid and enslaved education, "only made the Vietnamese people become buffaloes, the horse was extremely obedient, the slaves had blind eyes, deaf ears, and paralyzed limbs. How pitiful!" (Phan, 2000d: 181). Therefore, the task of developing education to expand knowledge, develop personality, and enhance the values and consciousness of the Vietnamese people, according to Phan Boi Chau, becomes an increasingly urgent task. That is what Phan Boi Chau is concerned about day and night. In the issue of "Education in our country", Phan Boi Chau affirmed: "The issue of education is a necessary thing in our country at that time" (Phan, 2000e: 213).

Phan Boi Chau has spent a lot of enthusiasm in researching and proposing educational issues through his writings and works, such as "New Vietnam"(Tan Viet Nam), "The letter is written in blood from foreign countries" (Hai ngoai huyet thu), "The issue of educatin-the use and value of literature" (Van de giao duc-cong dung va gia tri của van chuong), "National men need to know" (Nam quoc dan tu tri), "National women need to know" (Nu quoc dan tu tri), "Medicine to cure poor diseases" (Thuoc chua benh ngheo), Thien ho! De ho!... He also presented quite systematically on the motto and content of the education; and he also pointed out the highest purpose and meaning of education, in which, according to him, education is to improve the intellect, soul and consciousness of Vietnamese people; Since then, the Vietnamese people will have enough qualifications and bravery to stand up and expel the French colonialists, regain their freedom and independence for themselves and the nation. Education is not only meaningful and effective for enhancing the human value of each person, but more broadly, it also has great significance for the destiny and development of the nation and nation. Education will contribute to making people sacrifice private interests for the common good, making the country rich and strong. Phan Boi Chau wrote: "If we pay attention to education, we can give up our private work and follow the benefits, and make the rich and strong country move forward" (Phan, 2000b:185). 
In the view of human perfection education, Phan Boi Chau has analyzed and explained quite deeply the meaning of the concept of education. In The issue of education - the use and value of literature, he wrote: "Two words of education were originally in Chinese, but now they have become the Vietnamese language, education means teaching, education means feeding"(Phan, 2000e: 213), "Unconcerned Europe or Asia, East or West, white people or yellow people, it is necessary to worry about life, but the reason to preserve life, it is necessary to have farming. The nourishment must have two methods, one is to feed the flesh, the second to feed the spirit, to have the spirit of wisdom, then the flesh will be useful, but if the flesh is strong and good, then the spirit can be. prop. Therefore, education is indispensable, even for a day" (Phan, 2000e: 213)

Phan Boi Chau believes that education is a common job of the government and the whole society. It is necessary for everyone, because "we study mainly to learn to be human" (Phan, 2000f: 295), regardless of whether big or small, boy or girl, rich or poor, luxury or cowardice. Phan Boi Chau wrote: "Everything that our people need to learn, we invite teachers, open schools so that any people in our country can be rich, poor, cowardly, boys and girls, who are five years old or older, they will go to school in their childhood institute to be educated by the childish level; eight years old or older, then enter the primary school to take the education of the elementary level; fourteen years old or older, then enter high school to be under the education of the high school; By the age of eighteen, the talents were quite good, then went to the college to take the professional college education" (Phan, 2000f:184). In addition, he also advocated "setting up the Institute of Charityization to educate the criminals to be imprisoned; the stance teaches the blind, the mute, the deaf, the poor and pitiful; building houses for orphans, homes for the elderly, and maternity homes for midwives. Schools of poor and orphaned children must be attended by talented teachers who have compassion for their teachers, and take care of them so that our people can enjoy peace and happiness" (Phan, 2000b: 189).

In particular, Phan Boi Chau is very interested in the education of soldiers and women. Because, soldiers are those who have to give their lives to preserve the country, protect and help all people in society. And women are the people who have great responsibilities in society, with the role of motherhood, wives, raising children, helping husbands and children and who have a direct influence on intelligence, emotions and personality. of children from an early age. Phan Boi Chau wrote: "The soldier has the duty to help the farmers and the merchants, to open the land to move the people, to strengthen the country position, to increase the rights of the people. If there is no thoughtful education, how dare a soldier give up on himself for the sake of the country, out of love for his compatriots, building an inheritance, and the country will become more and more prosperous..." (Phan, 2000b: 185-186).

"Women are responsible for being good mothers, good wives, knowledgeable about poetry, or trade, are good at teaching children and helping soldiers. A good mother can give birth to a good child, a good wife can have a good husband" (Phan, 2000b: 185). Moreover, Phan Boi Chau also affirmed, if in the country "there are no patriotic women, that country will only be her servant. In a country that is neo-female, the education of women is very important. Books to teach women must choose good books or books. Schools to teach women must choose better and better teachers... How can women in the country, everyone want to be a good mother, want to be a gentle wife, want to be a woman clever" (Phan, 2000b: 121). Not only that, in the spirit of high humanity, Phan Boi Chau also pays special attention to education and vocational training for offenders. In order to complete their studies and reforms, they "leave unemployed. must go to the point of making mistakes" (Phan, 2000b: 183).

\section{The educational content and educational method in Phan Boi Chau's thought}

Stemming from the urgent requirement of the history of Vietnamese society in the late nineteenth century and early twentieth century, it was the issue of human liberation and national liberation, Phan Boi Chau focused on educational content. He said that the content of education must be comprehensive; must educate both education, ethics and physical education; educate both natural sciences to social sciences; 
educate about moral qualities, benevolence, meaning, ceremony, wisdom, trust, respect, need, thrift, honesty, loyalty, integrity, integrity, speech and conduct. In particular, with a very progressive viewpoint, Phan Boi Chau advocates the need to educate new knowledge about science, economics, military, jurisprudence, information, industry, agriculture and commerce, forestry, medicine and new ideological, socio-political issues, such as the ideology of democracy, civil rights, national power, independence, selfreliance, freedom and equality. In general, it is to educate Vietnamese people about human religion, such as: childhood, fatherhood, motherhood; It is the education of human obligations, such as: obligations to oneself, obligations to families, obligations to society, obligations to nations, peoples... In particular, attention should be paid to educating love. nation, national awareness and education of useful things for the people for the country. Phan Boi Chau wrote: "At the court, under the society, they all cared wholeheartedly about education, education, and physical training, not missing anything. Learn China, study Japan, study Europe, learn all kinds of things. Young-brunettes, educational institutions, elementary schools, high schools, universities all over the countryside, everywhere ... How to open schools, organize learning, teach and appoint successful learners, both imitating the good and the good of countries like Japan and Europe. Study philosophy, literature, history, politics, economics, military, law... Study industry, commerce, agriculture, female workers, medicine, forestry... Before entering primary school, then Everyone knew the Vietnamese language, was able to see the press, read new and new news; read the essays discussed. People knowledge was expanded from there. Once you have entered primary school, you will be able to increase your national status with all your study. Moreover, the books of primary, secondary and university education in the time compiled by the Ministry of Education imitate the general discussion and review in the parliament. All the contents of the book are intended to open up the patriotism and mutual trust in each other, to enlighten the people, to help the people rights, to make everyone progress thousands of miles away" (Phan, 2000b: 184-185).

In particular, due to our country's low level of production techniques and the requirements of our country's career development, from that time, Phan Boi Chau has paid great attention to the development of schools. vocational training should educate the country. In the work of Tan Viet Nam, he wrote: "The public schools must open all over the country to train workers. Miner, gold smoker, gunner, machine builder, commodity maker for trade, smith for plowing tools, skilled drawers, good tailors, for up to a hundred things. There are workers"(Phan, 2000b: 188).

With a lifelong desire to take care of education for the people of our country, Phan Boi Chau also gave an educational motto for the country's education, that: "It should be divided into three periods. A young person from the age of six is going to be ten, six years old is the first period, it should only be allowed to learn by old education, to practice for it with the old moral ethics, but the public works during school time focus on Quoc ngu and Chinese literature, and let him know many common common sense, such as raising a baby, let him drink breastmilk, that was the first period. Even more is the second period, when the nation from sixteen years old is about to rise until the age of twenty-four, twenty-five years old will use it by new education, specializing in teaching it in Western literature, but also mixed in some Chinese literature. But the first focus is on intellectual science, which is the formation of a useful talent, which will welcome people to embrace the current and future trends, which is the second period. Moving forward to another period that is the third period... It is a mixed Eurasian, neoconditional education"(Phan, 2000e: 215).

In the view of human perfecting education, along with the need to innovate both the content and methods of education and exams, Phan Boi Chau advocates that education must come from the requirements of the commune's practice. Assembly, abandoning the fictional learning and education must have an abundance of good things of the old combined with learning, selectively absorbing the new, to expand the people knowledge and improve the people. Because according to him: "People with a traumatic spirit can recruit talented people to teach them useful learning and give up fictional learning, still respect the goodness of 
the holy book, which must supplement Thai Tay's learning. The exams set up new regulations, not the exams were plain" (Phan, 2000a: 99). In the motto and methodology, Phan Boi Chau also advocates inviting "talented people from Europe and Japan to be teachers" to teach. (Phan, 2000b: 188).

Not only that, he also proposed to renovate and develop education that should be combined with sending people to train and study abroad, "granting scholarships to study abroad well to help train talented people for the land. successful country" (Phan, 2000a: 99),"some people study abroad to promote talent up" (Phan, 2000c: 294).

\section{CONCLUSION}

In summary, it can be said that the view of education in Phan Boi Chau's thought is one of the outstanding contents, showing his profound human values. By inheriting in the critical spirit of the old education content, as well as absorbing and selecting progressive elements in Western educational content and methods, Phan Boi Chau affirms that education is not only is a model for the training, training and comprehensive development of Vietnamese human intelligence, both knowledge in the field of social sciences as well as knowledge in the fields of natural sciences and technical sciences. but education is also a model, having great effects in cultivating, training, developing and perfecting personality, raising patriotism and national awareness for Vietnamese people; in order for our people to have the full capacity, spirit and courage to stand up and expel the French colonialists, regain independence and freedom for the nation, building the country to become increasingly rich and powerful. Therefore, Phan Boi Chau has advocated for building and developing a comprehensive education in both knowledge, morality and physics; educate both knowledge of the natural sciences and knowledge of the social sciences; An education that combines the inheritance of the nation's fine educational traditions with understanding of the values of the era in both its content, motto and educational methods.

Therefore, Phan Boi Chau was considered by Ho Chi Minh as "a hero, an angel, who gave his life for independence, and was worshiped by twenty million people in slavery." (Ho, 2000: 172.) These views of Phan Boi Chau are still useful lessons for the education and training career in Vietnam today, especially his practical and comprehensive educational philosophy.

\section{REFERENCES}

1. Phan, B. C. (2000a). Toan tap, vol 1, Hue: The Publishing House Thuan Hoa.

2. Phan, B. C. (2000b). Toan tap, vol 2, Hue: The Publishing House Thuan Hoa.

3. Phan, B. C. (2000c). Toan tap, vol 3, Hue: The Publishing House Thuan Hoa.

4. Phan, B. C. (2000d). Toan tap, vol 5, Hue: The Publishing House Thuan Hoa.

5. Phan, B. C. (2000e). Toan tap, vol 7, Hue: The Publishing House Thuan Hoa.

6. Phan, B. C. (2000f). Toan tap, vol 9, Hue: The Publishing House Thuan Hoa.

7. Tran, V. G. (1997). The development of thought in Vietnam from the nineteenth century to the August Revolution, volume 2: The bourgeois ideology and its inability to face historical missions. Hanoi: The Publishing House National Politics. 